\title{
Dry Etching Characteristics of Zinc Oxide Thin Films in $\mathrm{Cl}_{2}$-Based Plasma
}

\author{
Jong-Chang Woo, Tae-Kyung Ha, Chen Li, Seung-Han Kim, and Jung-Soo Park \\ School of Electrical and Electronics Engineering, Chung-Ang University, Seoul 156-756, Korea
}

Kyung-Mu Heo

Department of Renewable Energy, Chung-Ang University, Seoul 156-756, Korea

\author{
Chang-II Kim ${ }^{\dagger}$ \\ School of Electrical and Electronics Engineering and Department of Renewable Energy, Chung-Ang University, \\ Seoul 156-756, Korea
}

Received February 5, 2011; Revised March 15, 2011; Accepted March 19, 2011

\begin{abstract}
We investigated the etching characteristics of zinc oxide $(\mathrm{ZnO})$ and the effect of additive gases in a $\mathrm{Cl}_{2}-$ based inductively coupled plasma. The inert gases were argon, nitrogen, and helium. The maximum etch rates were 44.3, 39.9 , and $37.9 \mathrm{~nm} / \mathrm{min}$ for $\mathrm{Cl}_{2}(75 \%) / \mathrm{Ar}(25 \%), \mathrm{Cl}_{2}(50 \%) / \mathrm{N}_{2}(50 \%)$, and $\mathrm{Cl}_{2}(75 \%) / \mathrm{He}(25 \%)$ gas mixtures, $600 \mathrm{~W}$ radiofrequency power, $150 \mathrm{~W}$ bias power, and 2 Pa process pressure. We obtained the maximum etch rate by a combination of chemical reaction and physical bombardment. A volatile compound of $\mathrm{Zn}-\mathrm{Cl}$. achieved the chemical reaction on the surface of the $\mathrm{ZnO}$ thin films. The physical etching was performed by inert gas ion bombardment that broke the $\mathrm{Zn}-\mathrm{O}$ bonds. The highly oriented (002) peak was determined on samples, and the (013) peak of $\mathrm{Zn}_{2} \mathrm{SiO}_{4}$ was observed in the $\mathrm{ZnO}$ thin film sample based on x-ray diffraction spectroscopy patterns. In addition, the sample of $\mathrm{Cl}_{2} /$ He chemistry showed a high full-width at half-maximum value. The root-mean-square roughness of $\mathrm{ZnO}$ thin films decreased to $1.33 \mathrm{~nm}$ from $5.88 \mathrm{~nm}$ at $\mathrm{Cl}_{2}(50 \%) / \mathrm{N}_{2}(50 \%)$ plasma chemistry.
\end{abstract}

Keywords: Etch, Inductively coupled plasma, Zinc oxide, $\mathrm{Cl}_{2}, \mathrm{He}, \mathrm{Ar}, \mathrm{N}_{2}$

\section{INTRODUCTION}

The applications of zinc oxide $(\mathrm{ZnO})$ include thin film solar cells, piezo-electric devices, sensors, and photo detectors. $\mathrm{ZnO}$ thin film has attracted interest due to electronic and optical properties, such as $3.3 \mathrm{eV}$ direct band gap energy, high exciton binding energy of $60 \mathrm{meV}$, and high optical transmission (above 80\%) [1-3]. The advantages of $\mathrm{ZnO}$ thin film include easy to control electrical and optical properties through doping, and low cost. Patterning is an essential process to make a device. The fine electrodes are needed to obtain fine resolution of pixels. This is required to obtain fine device features. In recent years, device sizes have de-

${ }^{\dagger}$ Author to whom all correspondence should be addressed: E-mail: cikim@cau.ac.kr creased following with the size of devices diminishing by degrees. A conventional wet etch process does not satisfy the requirements of nano-scale feature size due to the property of isotropy. However, the dry etching process for $\mathrm{ZnO}$ thin film is necessary for advanced device fabrication due to its anisotropic etching property. Dry etching has been used in the fabrication process of ZnO-based devices. Plasma-induced damage causes critical errors in optoelectronic device action. In recent years, the $\mathrm{ZnO}$ studies have attempted to improve material performance. However, insufficient studies are available on $\mathrm{ZnO}$ thin film plasma etching.

In this work, we investigated the etching characteristics of $\mathrm{ZnO}$ thin film and the physical effect of inert gases in an inductively coupled plasma (ICP) system. The etching characteristics of $\mathrm{ZnO}$ thin film were investigated, as a function of the $\mathrm{Cl}_{2} / \mathrm{N}_{2}, \mathrm{Cl}_{2} / \mathrm{He}$, 


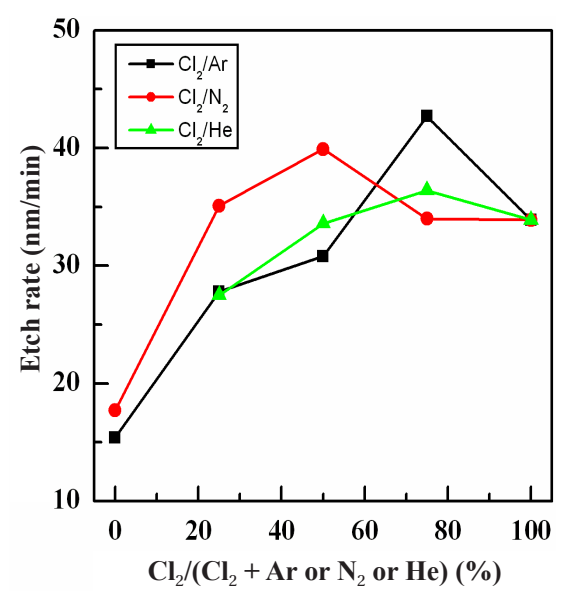

(Total flow rate is $20 \mathrm{sccm}$ )

Fig. 1. Etch rate of zinc oxide thin film, as a function of novel gas content in $\mathrm{Cl}_{2}$ plasma.

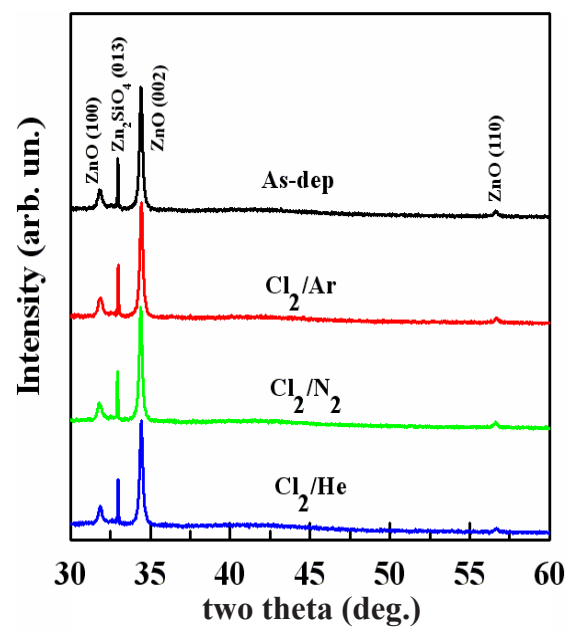

Fig. 2. Zinc oxide diffraction patterns of samples after dry etching at $\mathrm{Cl}_{2} / \mathrm{Ar}, \mathrm{Cl}_{2} / \mathrm{N}_{2}$, and $\mathrm{Cl}_{2} / \mathrm{He}$ plasma.

and $\mathrm{Cl}_{2} / \mathrm{Ar}$ gas mixing ratios. The physical effect of inert gas on the thin film state was investigated using X-ray diffraction (XRD) spectroscopy. The surface morphology of $\mathrm{ZnO}$ thin films was determined using atomic force microscopy (AFM).

\section{EXPERIMENTAL DETAILS}

Two hundred nm-thick $\mathrm{ZnO}$ thin films were grown on $\mathrm{Si}$ substrates using atomic layer deposition. We investigated the etch rate of the $\mathrm{ZnO}$ thin film using $\mathrm{Cl}_{2}$-based chemistry plasma mixed with $\mathrm{Ar}, \mathrm{N}_{2}$, and $\mathrm{He}$ gas. The inert gas flow rate was increased from $5 \mathrm{sccm}$ to $20 \mathrm{sccm}$ in $\mathrm{Cl}_{2}$ plasma. The experiment set four parameters: $20 \mathrm{sccm}$ flow rate, $600 \mathrm{~W}$ radio-frequency (RF) power, $150 \mathrm{~W}$ bias power, and 2 Pa process pressure. Experiments were performed by changing a specific inert gas, whilst maintaining the other parameters at the base condition. The etch rate of the $\mathrm{ZnO}$ thin films was determined using a surface profiler (Alpha-Step 500; KLA Tencor, Sanjoe, Ca, USA). The physical effects on the etched $\mathrm{ZnO}$ thin films were determined by XRD (D8-Advance; Bruker AXS Co., Karlsruhe, Germany). The XRD equipment consisted of the line detector, monochromator, and horizontal/vertical angle goniometer. The measurement

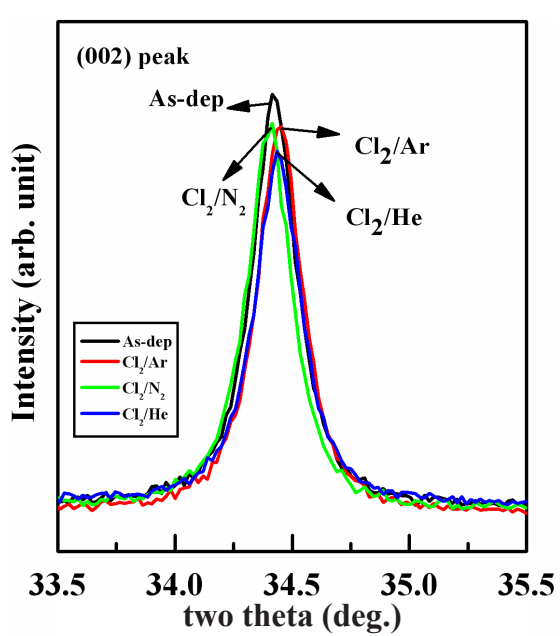

Fig. 3. Zinc oxide diffractogram of (002) peak at as-deposition, $\mathrm{Cl}_{2} / \mathrm{Ar}$, $\mathrm{Cl}_{2} / \mathrm{N}_{2}$, and $\mathrm{Cl}_{2} /$ He plasma.

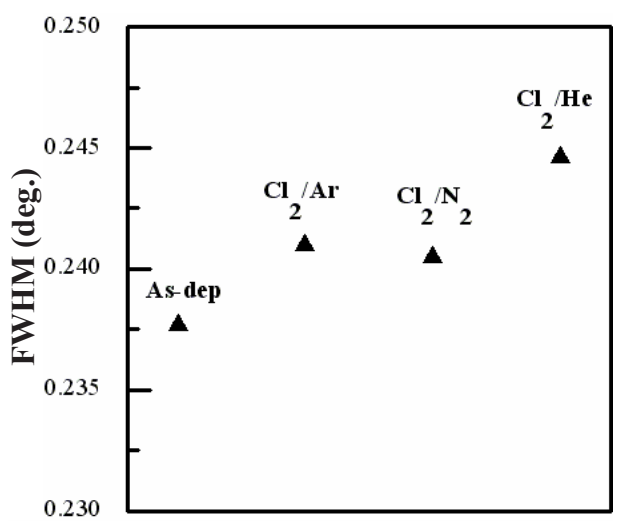

Fig. 4. Full-width at half-maximum (FWHM) value of X-ray diffraction patterns for each condition.

circle diameters were $435 \mathrm{~mm}, 500 \mathrm{~mm}, 600 \mathrm{~mm}$, or any intermediate value. The $\mathrm{X}$-ray diffractograms were scanned over an angular range of $30-65^{\circ}(2 \theta)$ with a step length of $0.02^{\circ}(2 \theta)$ using $\mathrm{Cu} \mathrm{K} \alpha 1$ radiation. The surface morphology was determined by non-contact AFM (NANO Station II; Surface Imaging Systems, Herzogenaurach, Germany). All samples were the $\mathrm{ZnO}$ thin film with a $1 \mathrm{~cm} \times 1 \mathrm{~cm}$ sample size.

\section{RESULTS AND DISCUSSION}

ZnO thin film etching experiments were performed in chlorine-based plasma. The objective of our experiment was to investigate the effect of the inert gas on $\mathrm{ZnO}$ thin film using $\mathrm{Cl}_{2}$ chemistry plasma.

Figure 1 shows the etch rate of $\mathrm{ZnO}$ as a function of the inert gas content in the $\mathrm{Cl}_{2}$ plasma. Figure 1 does not show data for $100 \%$ He flow, since it was very difficult to maintain stable process pressure for the $2 \mathrm{~Pa}$ condition in our ICP equipment. The maximum etch rates of the $\mathrm{ZnO}$ thin film were 44.3, 39.9, and $37.9 \mathrm{~nm} / \mathrm{min}$ at $\mathrm{Cl}_{2}(75 \%) / \operatorname{Ar}(25 \%), \mathrm{Cl}_{2}(50 \%) / \mathrm{N}_{2}(50 \%)$, and $\mathrm{Cl}_{2}(75 \%) / \mathrm{He}(25 \%)$ plasma. The chemical reactions on the $\mathrm{ZnO}$ thin film in $\mathrm{Cl}_{2}$ plasma were derived from the compound of $\mathrm{Zn}_{\mathrm{x}} \mathrm{Cl}_{\mathrm{y}}$ [4-7]. The $\mathrm{Zn}-\mathrm{Cl}$ compound was a volatile byproduct with a melting point of $290^{\circ} \mathrm{C}$. The ion bombardment of the novel gas ions supported the chemical reaction of $\mathrm{Cl}_{2}$ by break- 
(a)

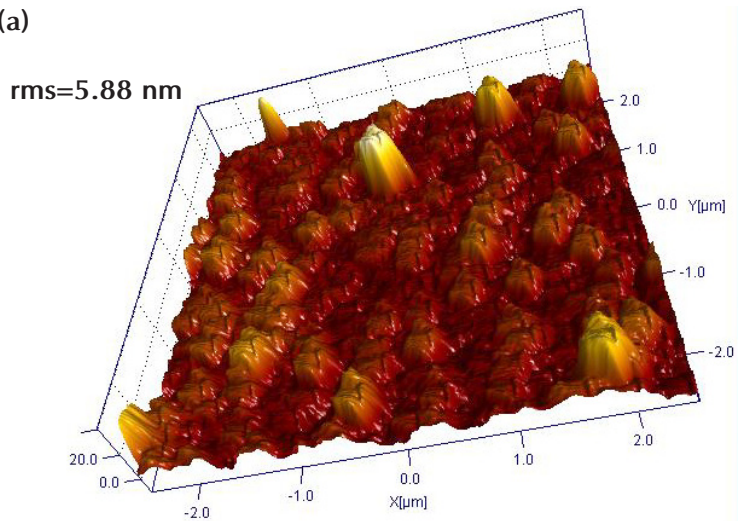

(b)

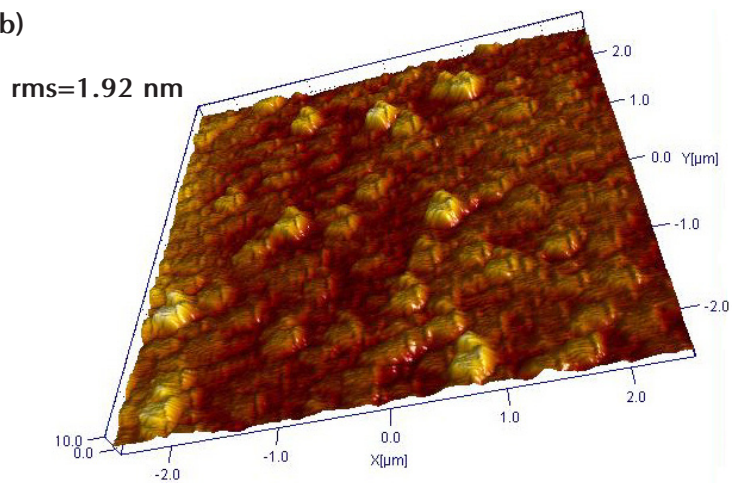

(c)
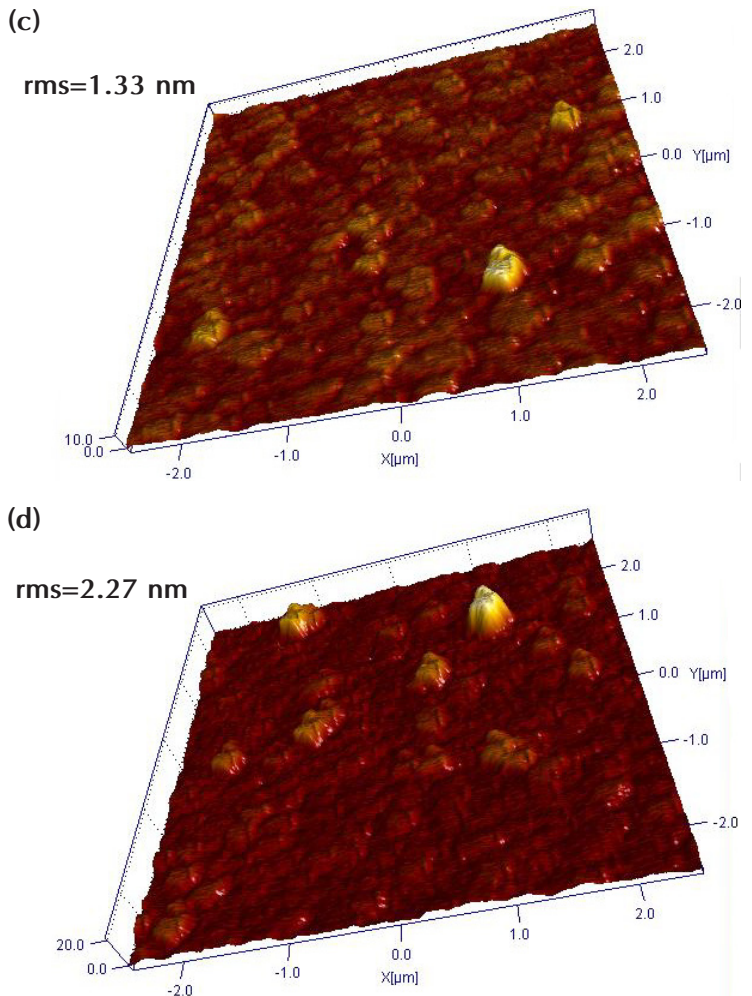

Fig. 5. Atomic force microscopy images for zinc oxide thin films (a) as-deposited, (b) etched in $\mathrm{Cl}_{2} / \mathrm{Ar}$ plasma, (c) etched in $\mathrm{Cl}_{2} / \mathrm{N}_{2}$ plasma, and (d) etched in $\mathrm{Cl}_{2} / \mathrm{He}$ plasma. RMS: root mean square.

ing the zinc oxide bonds. The results of the experiment indicated the noble gas induced physical etching and assisted the chemical reactions on the $\mathrm{ZnO}$ thin film.

Figure 2 shows XRD $2 \theta$ patterns of the $\mathrm{ZnO}$ films, as a function of the $\mathrm{Cl}_{2} / \mathrm{Ar}, \mathrm{Cl}_{2} / \mathrm{N}_{2}$, and $\mathrm{Cl}_{2} / \mathrm{He}$ gas mixing ratios and the as-de- posited sample. The XRD pattern of the $\mathrm{ZnO}$ thin films was used to investigate the physical effects of inert gas in plasma etching of $\mathrm{Cl}_{2}$-based chemistry. The $\mathrm{ZnO}$ diffraction pattern was obtained in conditions that indicated a high etch rate in the gas mixture ratio. As shown in Fig. 2, the $\mathrm{ZnO}$ peaks detected were (002), (100), and (110). The XRD patterns for $\mathrm{Cl}_{2} / \mathrm{Ar} \mathrm{Cl}_{2} / \mathrm{N}_{2}$, and $\mathrm{Cl}_{2} / \mathrm{He}$ plasma were similar to that of the as-deposited sample. In addition, the (013) peak of $\mathrm{Zn}_{2} \mathrm{SiO}_{4}$ appeared. This can be explained by the fact that $\mathrm{Zn}_{2} \mathrm{SiO}_{4}$ compound was detected in the interface of the two materials by the X-rays transmitted through $200 \mathrm{~nm}$ of the $\mathrm{ZnO}$ thin film to the Si substrate. The intensity of the peaks changed only slightly. This factor shows that metal chloride compounds $\left(\mathrm{Zn}_{\mathrm{x}} \mathrm{Cl}_{\mathrm{y}}\right)$ volatilized during the etching of the $\mathrm{ZnO}$ thin films and did not affect the stoichiometry of the $\mathrm{ZnO}$ thin films. The unchanged stoichiometry and small ion bombardment of the inert gases that flowed at 5 and $10 \mathrm{sccm}$ caused the crystallinity of the $\mathrm{ZnO}$ thin films to maintain and inhibit the creation of other crystal orientations. However, there was a possibility of crystalline damage in the structure of the $\mathrm{ZnO}$ thin film.

Figure 3 show the intensity of (002) peaks at each gas chemistry. The diffractogram of the as-deposition film sample shows the highest intensity in the (002) peak, while the other (002) peaks decreased in various plasma chemistry. In the $\mathrm{Cl}_{2} / \mathrm{N}_{2}$ and $\mathrm{Cl}_{2} / \mathrm{Ar}$ plasma chemistry, (002) peak intensity was decreased more than for the as-deposition film and peak intensity shows small difference between the $\mathrm{Cl}_{2} / \mathrm{N}_{2}$ and $\mathrm{Cl}_{2} / \mathrm{Ar}$ plasma. At the same time, (002) peak at the $\mathrm{Cl}_{2} / \mathrm{He}$ plasma exhibits lower intensity than the other peaks. These results allow us to assume that the $\mathrm{Cl}_{2} / \mathrm{He}$ chemistry during etching cause severe damage at the $\mathrm{ZnO}$ thin film surface.

Figure 4 shows the full-width at half-maximum (FWHM) values of the (002) peak for various gas mixtures. The experiments showed that the FWHM values of the etched $\mathrm{ZnO}$ films are higher than those of the as-deposited films. In this case, a high FWHM value means that the crystalline structure was incomplete [812]. These results indicate that ion bombardment during etching damaged the crystalline structure of the $\mathrm{ZnO}$ thin film surface. The different gas chemistry plasmas increased the FWHM values, indicating that the $\mathrm{ZnO}$ thin films have damaged crystalline due to ion bombardment. Degradation of crystallinity can be explained by inert gas ion bombardment creating an unstable crystalline structure. In addition, the $\mathrm{Zn}-\mathrm{O}$ bond breaking contributed to the unstable state in the $\mathrm{ZnO}$ thin films and degraded the crystallinity of the $\mathrm{ZnO}$ thin films. However, the range of fluctuation of FWHM values was too small $(\sim 0.1 \theta)$, which means that the crystalline damage-induced plasma etching definitely existed, even though it was infinitesimal.

Figure 5 shows a three-dimensional (3-D) AFM image of the etched $\mathrm{ZnO}$ thin films in $\mathrm{Cl}_{2}$-based plasma chemistry. Figure 5(a) shows that the root mean square (RMS) roughness of the asdeposited sample was $5.88 \mathrm{~nm}$. As shown in Fig. 5(b), the $\mathrm{ZnO}$ thin film sample using $\mathrm{Cl}_{2}(75 \%) / \mathrm{Ar}(25 \%)$ plasma exhibited 1.92 $\mathrm{nm}$ of RMS roughness. Figure 5(c) shows a sample with $\mathrm{Cl}_{2}(50 \%) /$ $\mathrm{N}_{2}(50 \%)$ chemistry that was determined by AFM to have $1.33 \mathrm{~nm}$ RMS roughness. Figure 5 (d) shows $\mathrm{Cl}_{2}(75 \%) / \mathrm{He}(25 \%)$ plasma etching experiment, and the sample shows a decrease of 2.27 nm of RMS roughness, as shown in Fig. 5(d). The etched samples exhibited lower RMS roughness than the as-deposited sample based on the etching experiments.

\section{CONCLUSIONS}

We investigated the effect of inert gas additives on $\mathrm{ZnO}$ thin films in $\mathrm{Cl}_{2} / \mathrm{Ar}, \mathrm{Cl}_{2} / \mathrm{N}_{2}$, and $\mathrm{Cl}_{2} / \mathrm{He}$ plasmas. The novel gas additive influenced the physical state of the $\mathrm{ZnO}$ thin film. The maximum etch rates were $44.3,39.9$, and $37.9 \mathrm{~nm} / \mathrm{min}$ at a gas 
mixture of $\mathrm{Cl}_{2}(75 \%) / \operatorname{Ar}(25 \%), \mathrm{Cl}_{2}(50 \%) / \mathrm{N}_{2}(50 \%)$, and $\mathrm{Cl}_{2}(75 \%) /$ $\mathrm{He}(25 \%), 600 \mathrm{~W}$ RF power, $150 \mathrm{~W}$ bias power, and 2 Pa process pressure. Oriented (002), (100), and (110) ZnO peaks were detected by XRD analysis. In addition, a (013) $\mathrm{Zn}_{2} \mathrm{SiO}_{4}$ peak was obtained from the XRD results. The etched samples exhibited high FWHM values at the (002) peak, indicating damage to the crystallinity. The surface roughness of the as-deposited sample was 5.88 $\mathrm{nm}$ in the 3-D AFM image. However, the surface roughnesses of the etched samples were lower than for the as-deposited sample, such as $1.92 \mathrm{~nm}$ at $\mathrm{Cl}_{2} / \mathrm{Ar}$ chemistry, $1.33 \mathrm{~nm}$ at $\mathrm{Cl}_{2} / \mathrm{N}_{2}$ chemistry, and $2.27 \mathrm{~nm}$ at $\mathrm{Cl}_{2} / \mathrm{He}$ chemistry. In addition, the He gas showed high roughness and a high FWHM value from XRD and AFM analysis results. We assume that the He ions were lighter than the other inert gas ions. Heavy ions were not accelerated as rapidly as light ions. The small He ion can permeate the $\mathrm{ZnO}$ thin film lattice. We assume that ion bombardment of the He ions caused more crystalline damage, and the effect of the He gas that makes the cooling substrate and stable plasma lead to a low etch rate due to the decreasing temperature for chemical reactions.

\section{REFERENCES}

[1] D. C. Look, Mater. Sci. Eng. B 80, 383 (2001) [DOI: 10.1016/ s0921-5107(00)00604-8].

[2] S. J. Peaton, D.P. Norton, K, Ip, Y. W. Heo, and T. Steiner, Prog.
Mater. Sci. 50, 293 (2005)

[3] D. C. Look, D. C. Reynolds, J. R. Sizelove, R. L. Jones, C. W. Litton, G. Cantwell, and W. C. Harsch, Solid State Commun. 105, 399 (1998) [DOI: 10.1016/s0038-1098(97)10145-4].

[4] W. Lim, L. Voss, R. Khanna, B. P. Gila, D. P. Norton, S. J. Pearton, and F. Ren, Appl. Surf. Sci. 253, 889 (2006) [DOI: 10.1016/ j.apsusc.2006.01.037].

[5] S. W. Na, M. H. Shin, Y. M. Chung, J. G. Han, S. H. Jeung, J. H. Boo, and N. E. Lee, Microelectron. Eng. 83, 328 (2006) [DOI: 10.1016/j.mee.2005.09.007].

[6] J. C. Woo, G. H. Kim, J. G. Kim, and C. I. Kim, Surf. Coat. Technol. 202, 5705 (2008) [DOI: 10.1016/j.surfcoat.2008.06.077].

[7] J. C. Woo, D. S. Um, and C. I. Kim, Thin Solid Films 518, 2905 (2010) [DOI: 10.1016/j.tsf.2009.10.144].

[8] J. L. van Heerden and R. Swanepoel, Thin Solid Films 299, 72 (1997) [DOI: 10.1016/s0040-6090(96)09281-4].

[9] G. Srinivasan and J. Kumar, Cryst. Res. Technol. 41, 893 (2006) [DOI: 10.1002/crat.200510690].

[10] K. K. Kim, J. H. Song, H. J. Jung, W. K. Choi, S. J. Park, and J. H. Song, J. Appl. Phys. 87, 3573 (2000) [DOI: 10.1063/1.372383].

[11] S. A. M. Lima, F. A. Sigoli, M. Jafelicci Jr, and M. R. Davolos, Int. J. Inorg. Mater. 3, 749 (2001) [DOI: 10.1016/s1466-6049(01)00055-1].

[12] M. A. Sobolewski, J. K. Olthoff, and Y. Wang, J. Appl. Phys. 85, 3966 (1999) [DOI: 10.1063/1.370298]. 